\title{
Efectos fisiológicos de los péptidos bioactivos derivados de las proteínas del lactosuero en la salud: Una revisión
}

\section{Physiological health effects of whey protein-derived bioactive peptides: A review}

\begin{abstract}
RESUMEN
El lactosuero es un subproducto derivado de la elaboración de queso. La calidad de la composición química de las proteínas del lactosuero las convierte en un sustrato ideal para la generación de péptidos con actividad biológica. La presente revisión tiene por objetivo analizar y discutir los efectos fisiológicos de los péptidos bioactivos derivados de las proteínas del lactosuero (PBDL) en la salud. Asimismo, este trabajo muestra detalladamente las estructuras químicas de las secuencias de los PBDL capaces de ejercer efectos favorables in vitro e in vivo e influir positivamente en los sistemas cardiovascular, endócrino e inmunológico. Sin embargo, las metodologías para generar PBDL de manera controlada, la dosificación y las concentraciones óptimas han sido poco exploradas. Por lo que es importante llevar a cabo investigación de frontera que permita avanzar el umbral del conocimiento vislumbrando la posibilidad de utilizar los PBDL como coadyuvantes en la prevención y tratamiento de enfermedades.
\end{abstract}

Palabras clave: Beneficios a la salud; Péptidos bioactivos; Proteínas derivadas del lactosuero.

\footnotetext{
ABSTRACT

Whey is a by-product of cheese production. The relevant chemical composition of whey proteins makes them an ideal substrate to release peptides with biological activity. The objective of this manuscript was to analyze and discuss the effects of whey-derived proteins bioactive peptides in health. Moreover, this review shows in detail sequences able to benefit human systems. Several in vitro and in vivo studies showed the capacity of these bioactive peptides to positively influence cardiovascular, endocrine and immune systems. However, the methodologies to obtain them in a controlled way, as well as dose and optimum concentrations have been scarcely explored. Therefore, it is necessary to conduct new research to improve knowledge that focuses on the possibility of using whey-derived bioactive peptides in the prevention and treatment of diseases.

Keywords: Bioactive peptides; Health benefits; Wheyderived proteins.
}

Ana Luisa Herrera-Ponce ${ }^{1}$, Alma Delia Alarcón-Rojo ${ }^{1}$, Iván Salmeron², José Carlos Rodríguez-Figueroa ${ }^{3}$.

\footnotetext{
1. Facultad de Zootecnia y Ecología. Universidad Autónoma de Chihuahua. Chihuahua, Chihuahua, México.

2. Facultad de Ciencias Químicas. Universidad Autónoma de Chihuahua. Chihuahua, Chihuahua, México.

3. Departamento de Ingeniería Química. Universidad de Sonora. Hermosillo, Sonora, México.
}

Dirigir correspondencia a: Dr. José Carlos Rodríguez Figueroa. Departamento de Ingeniería Química. Universidad de Sonora. Blvd. Luis Encinas y Rosales s/n. Col. Centro. Hermosillo, Sonora, México. Tel.: 6142436003. Email: jose.rodriguez@unison.mx

Este trabajo fue recibido el 04 de abril de 2018. Aceptado con modificaciones: 27 de julio de 2018. Aceptado para ser publicado: 11 de noviembre de 2018.

\section{INTRODUCCIÓN}

El lactosuero es un subproducto generado durante la elaboración de queso. Este contiene los componentes químicos hidrofílicos de la leche'. En general, $1 \mathrm{~kg}$ de queso se produce a partir de 10 litros de leche, lo que genera 9 litros de lactosuero. Por otro lado, el consumo de queso va en aumento, por lo que se estima un incremento de 130 millones de toneladas de lactosuero por año ${ }^{2,3}$.

El lactosuero se caracteriza por la calidad de los componentes químicos que lo conforman. Este subproducto está constituido por agua $(93 \%$, v/v), lactosa $(4.5-5 \%$, p/v), proteína $(0.6-0.8 \%$, $\mathrm{p} / \mathrm{v})$, lípidos $(0.4-0.5 \%$, $\mathrm{p} / \mathrm{v})$ y minerales (8-10\% extracto seco $)^{4}$, tales como calcio, magnesio, sodio, potasio, fosfato, citrato y cloruro ${ }^{5}$. 
Las proteínas del lactosuero juegan un papel importante en la nutrición, funcionalidad y actividad biológica ${ }^{1,5}$. El perfil proteico se muestra en la tabla 1. Estudios previos han reportado que las proteínas séricas presentan el mayor valor biológico ${ }^{6}$. Estas poseen péptidos encriptados que podrían ser liberados a través de procesos fermentativos ${ }^{7}$ o utilizando enzimas propias de la digestión natural o comerciales $^{6}$. La especificidad de la relación enzimasproteínas del lactosuero condiciona factores tales como composición, hidrofobicidad del C-terminal, masa molecular y orden de los aminoácidos en las secuencias peptídicas ${ }^{8}$, lo que impacta en la actividad biológica ${ }^{9}$. La interacción de estos factores puede generar péptidos inmunomoduladores, antihipertensivos, hipolipidémicos, antimicrobianos, antidiabéticos, anticarcinogénicos y antioxidantes, entre otros $^{10,11}$ capaces de beneficiar la funcionalidad de los sistemas cardiovascular, endócrino e inmunológico ${ }^{10}$.

El presente trabajo tiene por objetivo analizar y discutir los efectos fisiológicos de los péptidos bioactivos derivados de las proteínas del lactosuero en la salud, así como explorar las características de las estructuras químicas de las secuencias peptídicas asociadas a las actividades biológicas.

Las bases de datos de Elsevier, Springer, Wiley, Pubmed-NCBI, Scielo y Nature fueron consultadas para la elaboración de esta revisión. Los términos de búsqueda incluyeron: "whey peptides, angiotensin I-converting enzyme, antioxidant peptides, bioactive peptides sequences, cheese whey, antihypertensive activity, dipeptidyl peptidase-IV inhibitor, type 2 diabetes, immune function y whey protein hydrolysate". Se seleccionaron los artículos publicados en inglés y español durante los años 1997 y 2018.

\section{Sistema cardiovascular}

Las enfermedades cardiovasculares son la principal causa de muerte a nivel mundial ${ }^{12}$. Un tercio de la población mundial padece hipertensión arterial ${ }^{13}$. En la actualidad, para controlar esta enfermedad se prescriben fármacos tales como captopril, enalapril, lisinopril y alacepril. Sin embargo, se ha demostrado que la medicación a largo plazo puede tener efectos secundarios adversos ${ }^{10}$. Por lo que es importante explorar alternativas innovadoras que permitan mitigar este padecimiento ${ }^{14}$.

En los últimos años se ha estudiado el efecto de los péptidos en la salud. Los péptidos bioactivos derivados de las proteínas del lactosuero (PBDL) han demostrado influir positivamente sobre el sistema cardiovascular ${ }^{15}$. Estos han mostrado actividades hipocolesterolémica, antitrombótica, antioxidante y antihipertensiva ${ }^{16}$, por lo que su empleo podría coadyuvar en la prevención y el tratamiento de enfermedades cardiovasculares. Además, se ha reportado que los péptidos bioactivos de origen natural tienen alta afinidad por tejidos celulares por lo que son lentamente eliminados lo que les confiere mayor efecto antihipertensivo que las sustancias sintéticas ${ }^{17}$.

Uno de los principales mecanismos que regulan la presión arterial es el Sistema Renina-Angiotensina-Aldosterona. En donde la enzima convertidora de la angiotensina (ECA) hidroliza la angiotensina I en angiotensina II, la cual es un potente vasoconstrictor que incrementa la presión arterial ${ }^{18}$. En consecuencia, esta reacción produce la inactivación de la bradiquinina, que es un péptido vasodilatador ${ }^{11}$. Estudios previos han reportado la capacidad de los PBDL para inhibir competitivamente la actividad de la ECA, impidiendo así la liberación de angiotensina II y con ello vasodilatar el sistema. Cabe señalar que estos péptidos también pueden disminuir la alta presión arterial a través de otros mecanismos tales como la inhibición de la enzima convertidora de la endotelina, regulación inducida por efecto opioide, inhibición de la renina, inmunomodulación y antioxidación ${ }^{19}$.

La efectividad antihipertensiva de las secuencias de los PBDL está asociada a las características estructurales. En general, estos se constituyen por 2-20 aminoácidos ${ }^{11}$, peso molecular (PM) menor a $3 \mathrm{kDa}^{20} \mathrm{e}$ incluyen residuos hidrofóbicos y con carga positiva en el C-terminal ${ }^{21}$. El efecto in vivo e in vitro de estas secuencias sobre el sistema cardiovascular se muestra en las tablas 2 y 3 . Estas muestran el origen de la fracción proteica

Tabla 1. Perfil proteico del lactosuero.

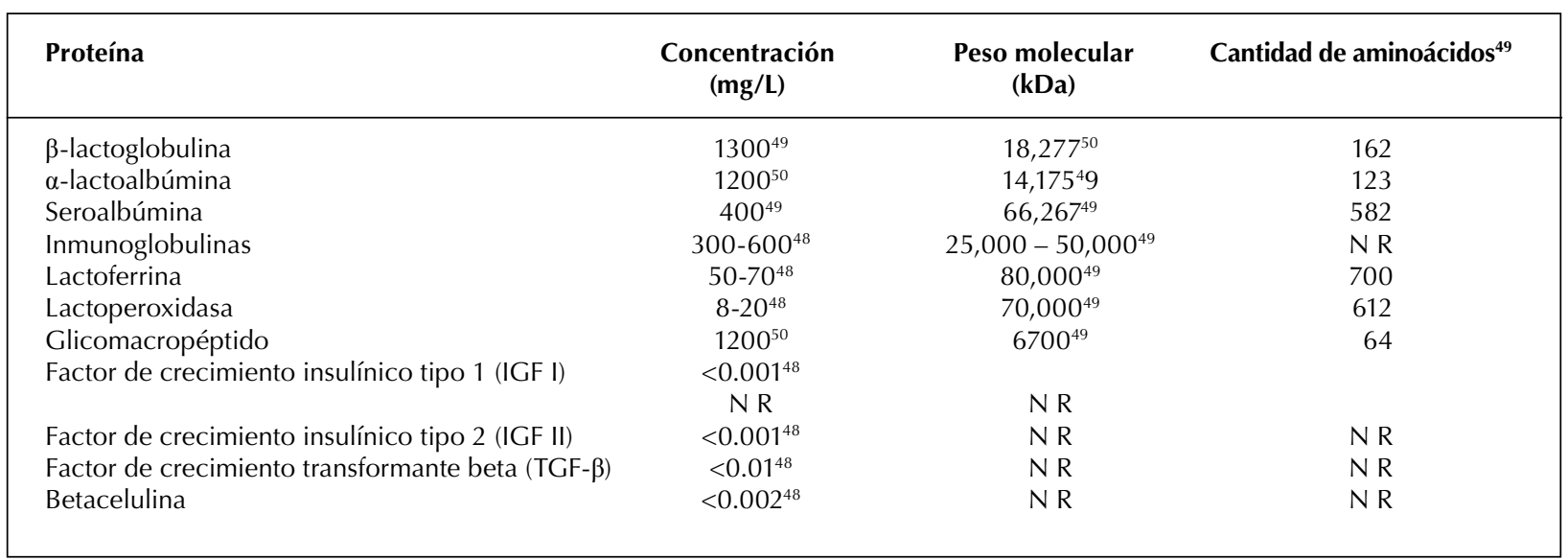

N R= No reportado. $(48=$ Simthers, 2008, 49= Eigel et al., 1984, 50= Brew et al., 1970) 
del lactosuero, la enzima hidrolítica, así como la secuencia peptídica liberada asociada al mecanismo de acción y a la magnitud en la que ejerce la bioactividad.

Hasta el momento, las secuencias peptídicas constituidas principalmente por aminoácidos hidrofóbicos IPA e YGLF han generado la máxima reducción de la presión arterial sistólica, $31^{22}$ y $23^{23} \mathrm{~mm} \mathrm{Hg}$, respectivamente (Tabla 2). Cabe señalar que ambas secuencias se derivaron de la fracción $\alpha$-lactoalbúmina. Por otro lado, se demostró que la presión arterial sistólica y diastólica no fue diferente significativamente entre los animales que ingirieron fracciones proteicas de leche fermentada $\operatorname{con} L$. lactis NRRL B-5057 y captopril durante 2 semanas ${ }^{20}$. Asimismo, estudios in vitro demostraron que el péptido GYGGVSLPEW proveniente de la fracción $\alpha$-lactoalbúmina, fue el que presentó la mayor capacidad para inhibir la actividad de la ECA (Tabla 3). Sin embargo, es necesario llevar a cabo ensayos in vivo que permitan establecer la magnitud de su potencial antihipertensivo.

Otra de las actividades biológicas que impactan positivamente al sistema cardiovascular es la hipocolesterolémica. La suplementación con proteína de lactosuero hidrolizada aumentó el colesterol de alta densidad en un modelo murino. De igual forma, los péptidos HIRL (f146-149) o $\beta$-lactotensina e IIAEK (f71-75) o lactostatina, ambos derivados de la $\beta$-lactoglobulina, disminuyeron los niveles de colesterol sérico y aumentaron la cantidad de colesterol de alta densidad en ratas ${ }^{24}$. También se ha reportado que este último péptido induce la transcripción de la enzima colesterol 7 - $\alpha$-hidroxilasa (CYP7A1), lo que genera un efecto hipocolesterolémico por la estimulación de la secreción de ácido biliarr ${ }^{25}$.

\section{Sistema endócrino}

La diabetes tipo 2 es una enfermedad constituida por un desorden crónico metabólico. Esta se caracteriza por la resistencia y la disminución de los niveles de insulina ${ }^{11}$, la cual es la más prevalente y está considerada como un problema de salud pública a nivel mundial. En el año 2000 se estimó que había 171 millones de diabéticos en el mundo, sin embargo, esta cifra podría alcanzar los 366 millones para el año $2030^{26}$.

En los últimos años se ha encontrado que la ingesta de proteínas de lactosuero ejerce un efecto fisiológico benéfico en el control del metabolismo de la glucosa. Estudios han reportado propiedades insulinotrópicas y reductoras de glucosa de las proteínas del lactosuero en sujetos sanos y con diabetes tipo 2. Las proteínas del lactosuero al parecer actúan vía aminoácidos y PBDL una vez liberados tras la digestión gastrointestinal. Estos últimos estimulan la liberación de diversas hormonas gastrointestinales tales como colecistoquinina, péptido YY, péptidos inhibidores de las incretinas gástricas y el péptido similar al glucagón tipo 1, lo que potencializa la secreción de insulina a partir de las células $\beta^{27}$.

Otra importante estrategia terapéutica en el tratamiento de la diabetes tipo 2 es la inhibición de la dipeptidil peptidasaIV (DPP-IV). Investigaciones previas han demostrado que estos péptidos bioactivos podrían ser utilizados por presentar capacidad inhibitoria endógena de la actividad de la enzima DPP-IV en el tracto gastrointestinal, previniendo la degradación de las incretinas insulinotrópicas GLP-1 y GIP27, 28 .

Diversas investigaciones in vitro e in vivo han demostrado la capacidad de los péptidos bioactivos derivados de las proteínas del lactosuero para reducir los niveles de glucosa. Hasta el momento no se conoce con exactitud el mecanismo de acción que se ejerce sobre la actividad enzimática de la DPP-IV. Sin embargo, las características estructurales juegan un papel clave en la inhibición de esta enzima ${ }^{11}$. Estos péptidos bioactivos presentan un $\mathrm{PM}<2 \mathrm{kDa}^{27}$, poseen grupos hidrofóbicos e incluyen prolina, alanina, leucina y valina en la segunda posición del grupo amino termina ${ }^{28}$. Los

Tabla 2. PBDL evaluados in vivo con influencia en el sistema cardiovascular.

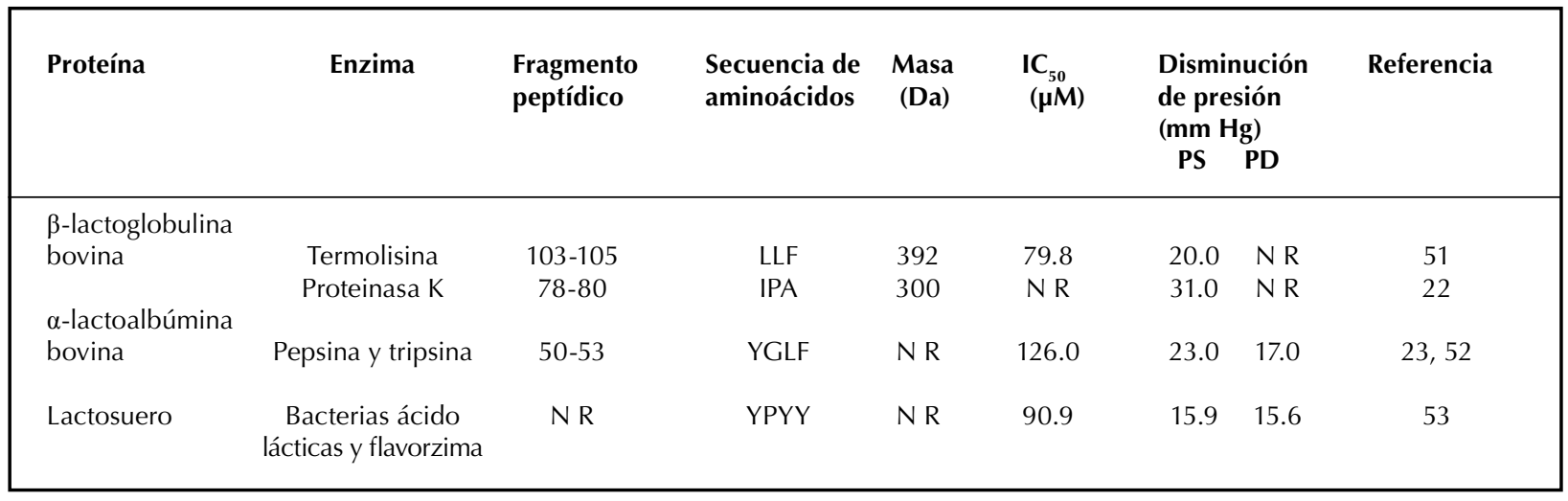

PBDL= Péptidos bioactivos derivados de las proteínas del lactosuero

WPDBP $=$ Whey protein-derived bioactive peptide

$\mathrm{PS}=$ Presión arterial sistólica

$\mathrm{PD}=$ Presión arterial diastólica

$\mathrm{N} R=$ No reportado

$\mathrm{IC}_{50}=$ Concentración peptídica necesaria para inhibir la actividad de la enzima convertidora de la angiotensina (ECA) en un $50 \%$. 
Tabla 3. PBDL evaluados in vitro con influencia en el sistema cardiovascular.

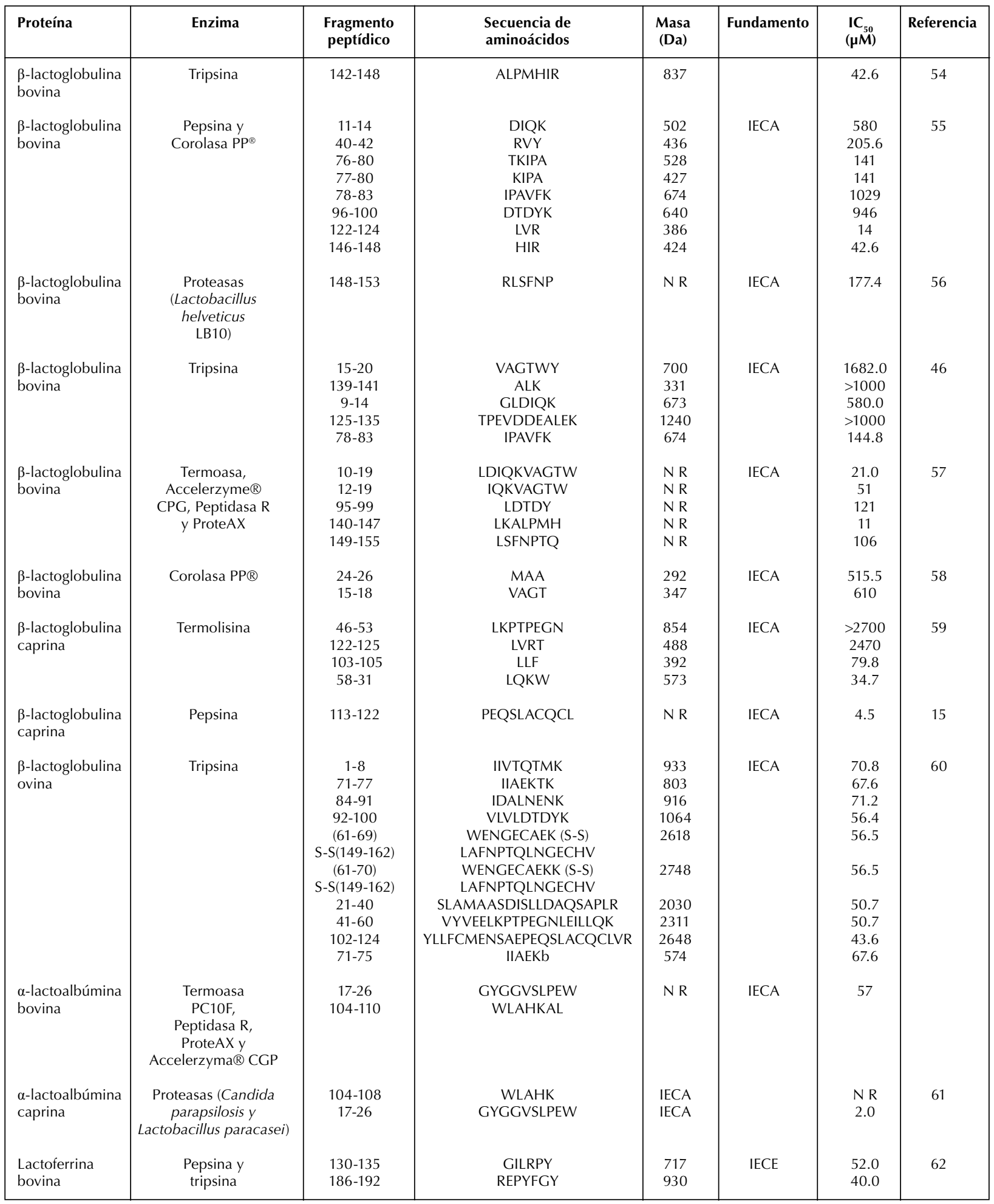

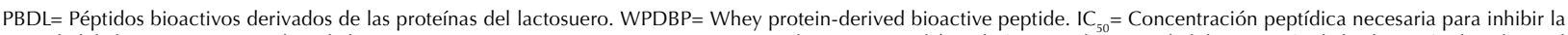

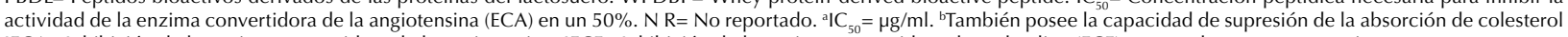
$\mathrm{IECA}=$ Inhibición de la enzima convertidora de la angiotensina. IECE= Inhibición de la enzima convertidora de endotelina (ECE) expresado como porcentaje. 
PBDL que inhiben la actividad de la DPP-IV se muestran en el Tabla 4. La máxima capacidad inhibitoria reportada es de $86 \%$ y $73 \%$, la cual está asociada a las secuencias NLEIILR y
LKPTPEGDL, respectivamente (Tabla 4). Ambas secuencias peptídicas fueron producto de la hidrólisis de la fracción $\beta$-lactoglobulina con papaína y pepsina, respectivamente.

Tabla 4. PBDL evaluados in vitro con influencia en el sistema endócrino ${ }^{\mathrm{a}}$.

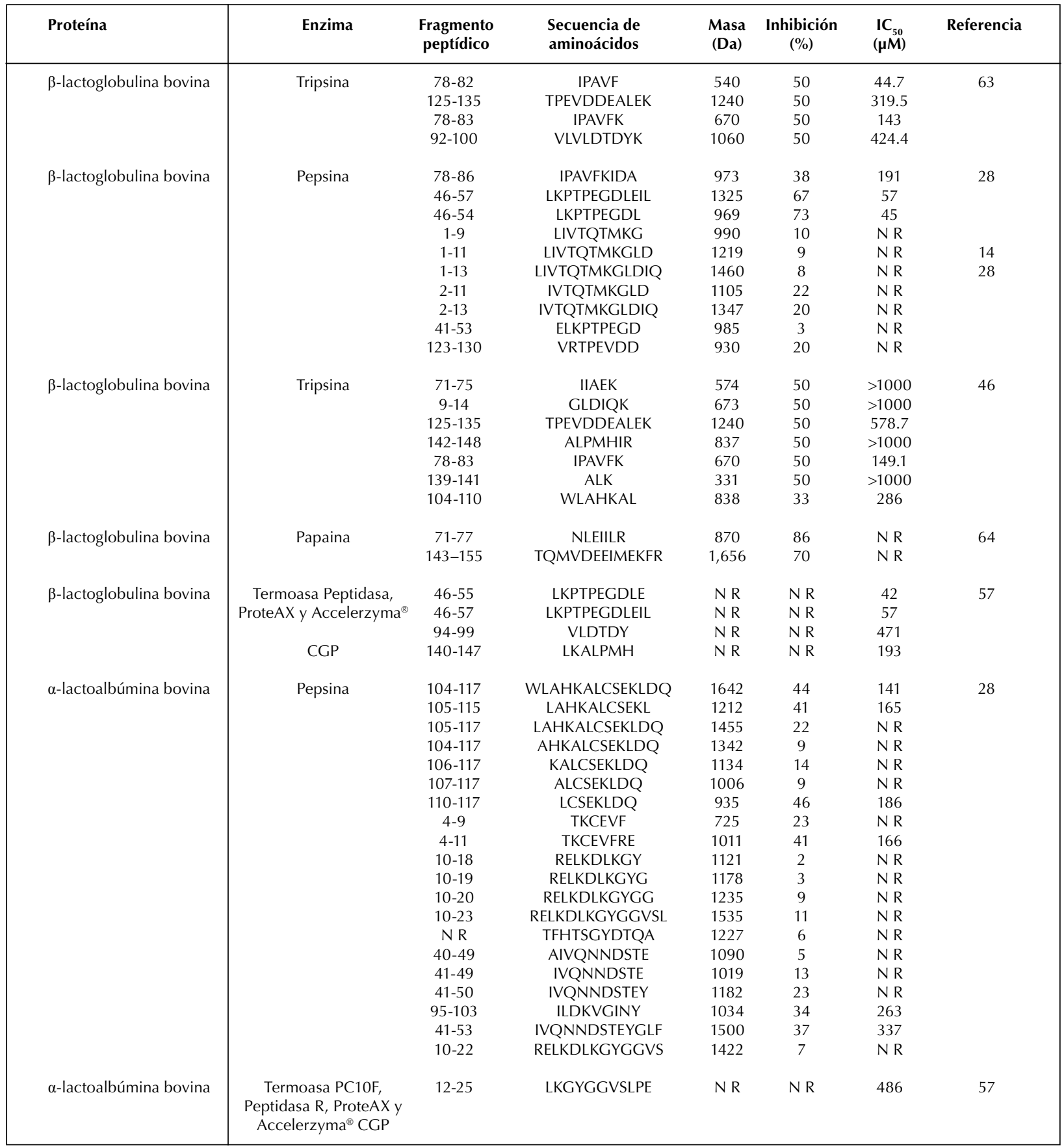




\section{Sistema inmunológico}

Los PBDL han demostrado efectos inmunomoduladores tanto a nivel de la respuesta inmune adaptativa como innata. Algunos ejemplos incluyen activación y proliferación de linfocitos, regulación de citoquinas, incremento de la síntesis de anticuerpos, aumento de la habilidad fagocítica de los macrófagos y estimulación de la generación de inmunoglobulinas ${ }^{29,30}$. El mecanismo de acción aún no ha sido dilucidado del todo, sin embargo se ha reportado que estos efectos podrían establecerse a nivel molecular a través de enlaces químicos entre los péptidos y los receptores de la superficie de las células del sistema imnunológico ${ }^{31}$.

La capacidad inmunomoduladora de los PBDL está en función de la estructura química. Aminoácidos, secuencia, longitud, carga, hidrofobicidad y estructura molecular del péptido definen esta capacidad. En general, los péptidos inmunomoduladores presentan 2-10 aminoácidos y naturaleza hidrofóbica ${ }^{30}$.

Diversos estudios in vitro e in vivo han demostrado la efectividad de los PBDL en el sistema inmunológico. Por ejemplo, Tang et al. (2009) incrementaron los niveles de IgA, IgG e IgM en cerdos tras la suplementación de la dieta con lactoferricina y lactoferrampina mejorando así la función inmune e intestinal ${ }^{32}$. Además, la lactoferricina ha mostrado capacidad para bloquear la actividad de la interleucina-6 (IL-6), citoquina relacionada con los procesos inflamatorios de la artritis reumatoide ${ }^{33}$. Saint-Sauveur et al. (2009) reportaron el aumento de la cantidad de IgA en ratones que fueron alimentados por 7 días con fracciones peptídicas del lactosuero induciendo la producción de interleucina-2 (IL-2) e interferón gama (IFN $\gamma$ ) que generan la activación de monocitos y neutrófilos ${ }^{34}$. Asimismo, se ha reportado que los PBDL mejoran la proliferación de linfocitos ${ }^{7}$, inhiben la liberación de la citoquina pro-inflamatoria IL- $3^{35}$ y la cantidad de especies reactivas de oxígeno en ratones ${ }^{29}$. Es importante señalar que los péptidos DIQKVAGTWYSLAMAASDIS (f11-30) y AMAASDISLLDAQSAPL (f23-39) indujeron la proliferación de células $T^{36}$.

Adicionalmente, la capacidad antioxidante de los PBDL ha demostrado influir positivamente en la función inmunológica ${ }^{37}$. Estudios in vivo han demostrado que la administración de hidrolizados del lactosuero aumentó los niveles de la enzima superóxido dismutasa (SOD), que inhibe radicales libres y aniones superóxidos ${ }^{38}$.

La principal relevancia de estos péptidos reside en la capacidad para reducir el estrés oxidativo, lo cual está relacionado con el envejecimiento y daño celular ${ }^{39}$. Existen diferentes mecanismos mediante los cuales se ejerce la capacidad antioxidante. Estos incluyen quelación de iones metálicos pro-oxidantes ${ }^{40}$, captación de radicales libres, inhibición de la peroxidación de lípidos, inactivación de especies reactivas de oxígeno, así como la combinación de éstas ${ }^{39}$. Los péptidos con gran capacidad antioxidante se han caracterizado por presentar una masa molecular menor a $3 \mathrm{kDa}^{41}$, por lo que el tamaño y la composición de los aminoácidos que conforman las secuencias peptídicas juegan un papel importante ${ }^{42,43}$. En este sentido, aminoácidos tales como fenilalanina, tirosina, triptófano e histidina actúan como queladores de iones metálicos; lisina dona átomos de hidrógeno y cisteína secuestra radicales libres ${ }^{44}$.

Las secuencias peptídicas derivadas de las fracciones proteicas del lactosuero con mayor efecto en el sistema inmunológico se muestran en la Tabla 5. Estas presentan un $\mathrm{IC}_{50}$ (concentración peptídica necesaria para inhibir la actividad oxidante en un $50 \%$ ) $<1 \mu \mathrm{M}$, provienen de la $\beta$-lactoglobulina, han sido liberadas por las enzimas corolasa $\mathrm{PP}^{45}$ y tripsina ${ }^{46}$ y están conformadas principalmente por aminoácidos hidrofóbicos, i.e. GLDIQK e IPAVFK.

Los PBDL también influyen en el sistema inmunológico mediante la actividad antimicrobiana ${ }^{47}$. En general, estos péptidos tienen una masa molecular $<10 \mathrm{kDa}$, punto isoeléctrico mayor de 10 y están compuestos por aminoácidos básicos, alifáticos y polares ${ }^{1,9}$. El mecanismo de acción de los péptidos con actividad antimicrobiana está basado en interacciones electrostáticas. La carga positiva de estos péptidos reacciona con la carga negativa de la membrana celular. Esto bloquea los sitios específicos en la interacción con calcio y magnesio, responsables de la integridad de la membrana, y forma poros que causan la pérdida de metabolitos y aumenta la permeabilidad a moléculas tóxicas con la consecuente muerte celular ${ }^{47}$.

Los hidrolizados de lactoferricina con pepsina han mostrado ejercer actividades biológicas. Las actividades antimicrobianas, antifúngica y una débil actividad antiviral representan las más importantes. Estas propiedades se deben a que forman estructuras anfipáticas ${ }^{48}$. Asimismo, se ha demostrado que la péptidos derivados de la hidrólisis del glicomacropéptido, $\beta$-lactoglobulina y $\alpha$-lactoalbúmina inhiben el crecimiento de bacterias Gram positivas?.

\section{CONCLUSIONES}

Los PBDL presentan relevantes efectos fisiológicos benéficos en la salud favoreciendo la función de los sistemas cardiovascular, endócrino e inmunológico. Las estructuras químicas de las secuencias peptídicas representan un punto clave en la ejecución de la bioactividad. Estas últimas están íntimamente relacionadas con la fracción proteica del lactosuero y la especificidad enzimática. Hoy en día los avances tecnológicos han permitido generar e identificar una amplia gama de secuencias peptídicas derivadas de las proteínas del lactosuero capaces de ejercer diversas funcionalidades. Sin embargo, las metodologías para liberarlos de manera controlada, la dosificación y las concentraciones óptimas han sido poco exploradas. Por lo que es importante llevar a cabo investigación de frontera que permita avanzar el umbral del conocimiento que permita el uso de los PBDL como coadyuvantes en la prevención y tratamiento de enfermedades de nuestros tiempos.

Agradecimientos. Los autores agradecen el financiamiento otorgado por CONACYT a través del Fondo Sectorial correspondiente al proyecto 258483 para la realización de este trabajo. 
Tabla 5. PBDL evaluados in vitro con influencia en el sistema inmunológico.

\begin{tabular}{|c|c|c|c|c|c|c|c|}
\hline Proteína & Enzima & $\begin{array}{l}\text { Fracción } \\
\text { peptídica }\end{array}$ & $\begin{array}{l}\text { Secuencia de } \\
\text { aminoácidos }\end{array}$ & $\begin{array}{c}\text { Masa } \\
(\mathrm{Da})\end{array}$ & Fundamento & $\begin{array}{c}\mathrm{IC}_{50}(\mu \mathrm{M}) \mathrm{o} \\
\text { cepa evaluada }\end{array}$ & Referencia \\
\hline$\beta$-lactoglobulina bovina & Corolasa PP ${ }^{\circledR}$ & $\begin{array}{c}19-29 \\
145-149 \\
42-46\end{array}$ & $\begin{array}{c}\text { WYSLAMAASDI } \\
\text { MHIRL } \\
\text { YVEELb }\end{array}$ & $\begin{array}{c}1225 \\
667 \\
650\end{array}$ & Antioxidante & $\begin{array}{l}2.6^{\mathrm{a}} \\
0.3^{\mathrm{a}} \\
0.8^{\mathrm{a}}\end{array}$ & 45 \\
\hline$\beta$-lactoglobulina bovina & Termolisina & $\begin{array}{c}58-61 \\
95-101 \\
151-155\end{array}$ & $\begin{array}{l}\text { LQKW } \\
\text { LDTDYKK } \\
\text { FNPTQ }\end{array}$ & $\begin{array}{l}573 \\
881 \\
605\end{array}$ & Antioxidante & $\begin{array}{l}\text { NR } \\
\text { NR } \\
\text { NR }\end{array}$ & 16,65 \\
\hline$\beta$-lactoglobulina bovina & Alcalasa & $\begin{array}{c}19-22 \\
\text { N R } \\
\text { N R } \\
81-82 \\
20-22 \\
\text { N R } \\
104-105\end{array}$ & $\begin{array}{l}\text { WYSL } \\
\text { AHLW } \\
\text { GTSV } \\
\text { VF } \\
\text { YSL } \\
\text { LAHL } \\
\text { LF }\end{array}$ & $\begin{array}{l}567 \\
525 \\
362 \\
265 \\
381 \\
452 \\
278\end{array}$ & Antioxidante & $\begin{array}{l}84.8 \\
74.0 \\
31.5 \\
19.7 \\
48.2 \\
63.0 \\
19.9\end{array}$ & 66 \\
\hline$\beta$-lactoglobulina bovina & Alcalasa & $\begin{array}{l}146-150 \\
75-82 \\
24-32\end{array}$ & $\begin{array}{c}\text { HIRLS } \\
\text { KTKIPAVF } \\
\text { MAASDISLL }\end{array}$ & $\begin{array}{l}624 \\
903 \\
936\end{array}$ & Antioxidante & $\begin{array}{l}\text { NR } \\
\text { NR } \\
\text { NR }\end{array}$ & 39 \\
\hline$\beta$-lactoglobulina bovina & Corolasa & $\begin{array}{l}43-49 \\
43-51\end{array}$ & $\begin{array}{c}\text { VEELKPT } \\
\text { VEELKPTPE }\end{array}$ & $\begin{array}{c}815 \\
1041\end{array}$ & Antioxidante & $\begin{array}{l}\text { NR } \\
\text { NR }\end{array}$ & 39 \\
\hline$\beta$-lactoglobulina bovina & Tripsina & $\begin{array}{c}15-20 \\
139-141 \\
71-75 \\
9-14 \\
125-135 \\
142-148 \\
78-83 \\
\end{array}$ & $\begin{array}{c}\text { VAGTWY } \\
\text { ALK } \\
\text { IIAEK } \\
\text { GLDIQK } \\
\text { TPEVDDEALEK } \\
\text { ALPMHIR } \\
\text { IPAVFK } \\
\end{array}$ & $\begin{array}{c}700 . \\
331 \\
574 \\
673 \\
1240 \\
837 \\
674 \\
\end{array}$ & Antioxidante & $\begin{array}{c}5.6 \mathrm{a} \\
0.01 \mathrm{a} \\
0.02 \mathrm{a} \\
0.02 \mathrm{a} \\
0.004 \mathrm{a} \\
0.04 \mathrm{a} \\
0.002 \mathrm{a} \\
\end{array}$ & 46 \\
\hline$\beta$-lactoglobulina bovina & $\begin{array}{c}\text { Tripsina y } \\
\text { quimotripsina }\end{array}$ & $36-42$ & SAPLRVY & 805 & Antimicrobiano & $\begin{array}{c}\text { L. monocytogenes, } \\
\text { S. aureus y } \\
\text { E. coli }\end{array}$ & 69 \\
\hline$\beta$-lactoglobulina bovina & Pepsina & $\begin{array}{c}14-18 \\
147-149 \\
123-125 \\
143-146 \\
134-136 \\
50-54 \\
\end{array}$ & $\begin{array}{l}\text { KVAGT } \\
\text { IRL } \\
\text { VRT } \\
\text { LMPH } \\
\text { EKF } \\
\text { PEGDL } \\
\end{array}$ & $\begin{array}{l}475 \\
401 \\
375 \\
497 \\
423 \\
530 \\
\end{array}$ & Antimicrobiano & $\begin{array}{l}\text { Bacterias G+ } \\
\text { Bacterias G- }\end{array}$ & 8 \\
\hline$\beta$-lactoglobulina caprina & $\begin{array}{c}\text { Proteasas } \\
\text { digestivas } \\
\text { humanas }\end{array}$ & $\begin{array}{c}1-8 \\
9-18 \\
21-32 \\
33-39 \\
43-55 \\
71-82 \\
92-100 \\
125-134 \\
139-147\end{array}$ & $\begin{array}{c}\text { IIVTQTMK } \\
\text { GLDIQKVAGT } \\
\text { SLAMAASDISLL } \\
\text { DAQSAPL } \\
\text { VEELKPTPEGDLE } \\
\text { IIAEKTKIPAVF } \\
\text { VLVLDTDYK } \\
\text { TPEVDDEALE } \\
\text { ALKALPMHI }\end{array}$ & $\begin{array}{c}933 \\
N R \\
N R \\
N R \\
N R \\
N R \\
1064 \\
N R \\
N R\end{array}$ & Antimicrobiano & E. coli & 71 \\
\hline
\end{tabular}


... continuación Tabla 5.

\begin{tabular}{|c|c|c|c|c|c|c|c|}
\hline Proteína & Enzima & $\begin{array}{l}\text { Fracción } \\
\text { peptídica }\end{array}$ & $\begin{array}{l}\text { Secuencia de } \\
\text { aminoácidos }\end{array}$ & $\begin{array}{l}\text { Masa } \\
\text { (Da) }\end{array}$ & Fundamento & $\begin{array}{c}\mathrm{IC}_{50}(\mu \mathrm{M}) \mathrm{o} \\
\text { cepa evaluada }\end{array}$ & Referencia \\
\hline$\alpha$ - lactoalbúmina bovina & $\begin{array}{c}\text { Tripsina } \\
\text { Quimotripsina }\end{array}$ & $\begin{array}{c}1-5 \\
(17-31) S- \\
S(109-114) \\
(61-68) S- \\
S(75-80)\end{array}$ & $\begin{array}{c}\text { EQLTK } \\
\text { GYGGVSLPEWVCTTF } \\
\text { ALCSEK } \\
\text { CKDDQNPHISCDKF }\end{array}$ & $\begin{array}{c}620 \\
2250 \\
1650\end{array}$ & $\begin{array}{l}\text { Antimicrobiano } \\
\text { Antimicrobiano }\end{array}$ & Bacterias G+ y G- & 71 \\
\hline$\alpha$ - lactoalbúmina bovina & Pepsina & $117-121$ & KVGIN & 530 & Antimicrobiano & L. ivanovii & 8 \\
\hline $\begin{array}{l}\text { Glicomacro-péptido } \\
\text { caprino }\end{array}$ & $\begin{array}{l}\text { Proteasas } \\
\text { digestivas } \\
\text { humanas }\end{array}$ & $\begin{array}{l}106-124 \\
109-121 \\
126-133 \\
130-139 \\
141-153\end{array}$ & $\begin{array}{l}\text { N R } \\
\text { N R } \\
\text { N R } \\
\text { N R } \\
\text { N R }\end{array}$ & $\begin{array}{l}\text { NR } \\
\text { NR } \\
\text { NR } \\
\text { NR } \\
\text { N R }\end{array}$ & Antimicrobiano & $\begin{array}{l}\text { E.coli y } \\
\text { B. cereus }\end{array}$ & 70 \\
\hline
\end{tabular}

PBDL= Péptidos bioactivos derivados de las proteínas del lactosuero

WPDBP $=$ Whey protein-derived bioactive peptide

a $\mu$ M equivalentes Trolox /mg de péptido

b También presenta actividad osteoblástica

$\mathrm{NR}=$ No reportado

$\mathrm{IC}_{50}=$ Concentración peptídica necesaria para inhibir la actividad oxidante en un 50\%.

\section{BIBLIOGRAFÍA}

1. Smithers GW. Whey-ing up the options - Yesterday, today and tomorrow. Int Dairy J 2015; 48: 2-14.

2. OECD/Food and Agriculture Organization of the United Nations. OECD-FAO Agricultural Outlook 2013, OECD Publishing. http://dx.doi.org/10.1787/agr_outlook-2013en

3. Prazeres AR, Carvalho F, Rivas J. Cheese whey management: A review. J Environ Manage 2012; 110: 48-68.

4. Jeličić I, Božanić R., Tratnik Lj. Whey based beverages-a new generation of dairy products. Mljekarstvo 2008; 58(3): 257274.

5. Nishanthi M, Vasiljevic T, Chandrapala J. Properties of whey proteins obtained from different whey streams. Int Dairy I 2017; 66:76-83.

6. Wijayanti HB, Bansal N, Deeth HC. Stability of Whey Proteins during thermal processing: A Review. Compr Rev Food Sci Food Saf 2014; 13: 1235-51.

7. Alvarado Carrasco C, Guerra M. Lactosuero como fuente de péptidos bioactivos. An venez nutr 2010; 23(1): 45-50.

8. Théolier J, Hammami R, Labelle P, Fliss I, Jean J. Isolation and identification of antimicrobial peptides derived by peptic cleavage of whey protein isolate. J Funct Foods 2013; 5: 706-14.

9. Esmaeilpour M, Ehsani MR, Aminlari M, Shekarforoush S, Hoseini E. Antimicrobial peptides derived from goat's milk whey proteins obtained by enzymatic hydrolysis. I -Food Biosci Technol 2017; 7(1): 65-72.

10. Adjonu R, Doran G, Torley P, Agboola S. Screening of whey protein isolate hydrolysates for their dual functionality: Influence of heat pre-treatment and enzyme specificity. Food Chem 2013; 136(3-4): 1435-1443.

11. Brandelli A, Daroit DJ, Corrêa APF. Whey as a source of peptides with remarkable biological activities. Food Res Int 2015; 73: 149-161.

12. World Health Organization. The top 10 causes of death. 2017. http://www.who.int/mediacentre/factsheets/fs310/en/
13. Onuh JO, Girgih AT, Malomo S, Aluko RE, Aliani M. Kinetics of in vitro renin and angiotensin converting enzyme inhibition by chicken skin protein hydrolysates and their blood pressure lowering effects in spontaneously hypertensive rats. I Funct Foods 2015; 14: 133-143.

14. Daliri EBM, Lee BH, Oh DH. Current trends and perspectives of bioactive peptides. Crit. Rev Food Sci Nutr 2017; 12: 1-12.

15. Ibrahim HR, Ahmed AS, Miyata T. Novel angiotensin-converting enzyme inhibitory peptides from caseins and whey proteins of goat milk. J Adv Res 2017; 8(1): 63-71.

16. Contreras MDM, Hernández-Ledesma B, Amigo L, MartínÁlvarez PJ, Recio I. Production of antioxidant hydrolyzates from a whey protein concentrate with thermolysin: Optimization by response surface methodology. LWT - Food Sci Technol 2011; 44(1): 9-15.

17. Koyama $M$, Hattori $S$, Amano $Y$, Watanabe $M$ Nakamura $K$. Blood pressure-lowering peptides from neo-fermented buckwheat sprouts: a new approach to estimating ACEinhibitory activity. PLoS One. 2014; 9(9):e105802.

18. Moslehishad M, Reza Ehsani M, Salami M, Mirdamadi S, Ezzatpanah H, Niasari A, Naslaji A, Akbar Moosavi-Movahedi A.The comparative assessment of ACE-inhibitory and antioxidant activities of peptide fractions obtained from fermented camel and bovine milk by Lactobacillus rhamnosus PTCC 1637. Int Dairy J 2013; 29(2): 82-87.

19. Nongonierma AB, FitzGerald RJ. Bioactive properties of milk proteins in humans: A review. Petides 2015; 73: 20-34.

20. Rodríguez-Figueroa JC, González-Córdova AF, Torres-Llanez MJ, Garcia HS, Vallejo-Cordoba B. Novel angiotensin l-converting enzyme inhibitory peptides produced in fermented milk by specific wild Lactococcus lactis strains. I Dairy Sci 2012; 95(10): 5536-5543.

21. O'Loughlin IB, Murray B, Brodkorb A, FitzGerald RJ, Kelly $P M$. Production of whey protein isolate hydrolysate fractions with enriched ACE-inhibitory activity. Int Dairy J 2014; 38(2): 101-103. 
22. Abubakar A, Saito T, Kitazawa H, Kawai Y, Itoh T. Structural analysis of new antihypertensive peptides derived from cheese whey protein by proteinase K digestion. I Dairy Sci 1998; 81(12): 3131-3138.

23. Nurminen ML, Sipola M, Kaarto H, Pihlanto-Leppala A, Piilola $K$, Korpela $R$, Tossavainen $O$, Korhonen $H$, Vapaatalo $H$. $\alpha$-Lactorphin lowers blood pressure measured by radiotelemetry in normotensive and spontaneously hypertensive rats. Life Sci 2000; 66(16): 1535-1543.

24. Nagaoka S, Futamura Y, Miwa K, Awano T, Yamauchi K, Kanamaru Y, Tadashi T, Kuwata T. Identification of novel hypocholesterolemic peptides derived from bovine milk beta-lactoglobulin. Biochem Biophys Res Commun 2001; 281(1): 11-17.

25. Morikawa K, Kondo I, Kanamaru Y, Nagaoka S. A novel regulatory pathway for cholesterol degradation via lactostatin. Biochem Biophys Res Commun 2007; 352(3): 697-702.

26. Wild S, Roglic G, Green A, Sicree R, King H. Global Prevalence of Diabetes. Estimates for the year 2000 and projections for 2030. Diabetes Care 2004; 27(5): 1047-1053.

27. Jakubowicz D, Froy O. Biochemical and metabolic mechanisms by which dietary whey protein may combat obesity and type 2 diabetes. I Nutr Biochem 2013; 24(1): 1-5.

28. Lacroix IME, Li-Chan ECY. Isolation and characterization of peptides with dipeptidyl peptidase-IV inhibitory activity from pepsin-treated bovine whey proteins. Peptides 2014; 54: 39-48.

29. Badr G, Sayed LH, Omar HE-DM, Abd El-Rahim AM, Ahmed EA, Mahmoud MH. Camel whey protein protects $B$ and $T$ cells from apoptosis by suppressing activating transcription factor-3 (ATF-3)-mediated oxidative stress and enhancing phosphorylation of $A K T$ and I $\kappa B-\alpha$ in type I diabetic mice. Cell Physiol Biochem 2017; 41-54.

30. Chalamaiah $M, W$. Yu, J. Wu. Immunomodulatory and anticancer protein hydrolysates (peptides) from food proteins: A review. Food Chem 2018; 245: 205-222.

31. Maestri E, Marmiroli $M$, Marmiroli N. Bioactive peptides in plant-based foodstuffs. J Proteomics 2016; 147: 104-155.

32. Tang Z, Yin Y, Zhang Y, Huang R, Sun Z, Li T, Chu W, Kong X, Li L, Geng M, Tu Q. Effects of dietary supplementation with an expressed fusion peptide bovine lactoferricina lactoferrampin on performance, immune function and intestinal mucosal morphology in piglets weaned at age 21 d. Br I Nutr 2009; 101: 998-1005

33. Barros de Oliveira CM, Kimiko Sakata $R$, Machado Issy A, Gerola LR, Salomão R. Citocinas y dolor. Rev Bras Anestesiol 2011; 61(2): 137-42.

34. Saint-Sauveur D, Gauthier SF, Boutin Y, Montoni A, Fliss I. Effect of feeding whey peptide fractions on the immune response in healthy and Escherichia coli infected mice. Int Dairy J 2009; 19: 537-544.

35. Piccolomini AF, Iskandar MM, Lands LC, Kubow S. High hydrostatic pressure pre-treatment of whey proteins enhances whey protein hydrolysate inhibition of oxidative stress and IL-8 secretion in intestinal epithelial cells. Food Nutr Res 2012; 56: $1-10$.

36. Gouw JW, Jo J, Meulenbroek LAPM, Heijjer S, Kremer E, Sandalova $E$, Knulst AC, Jeurink $P$, Garssen J, Rijnierse $A$, Knippels LMJ. Identification of peptides with tolerogenic potential in a hydrolyzed whey-based infant formula. Clin Exp Allergy 2018, doi: 10.1111/cea.13223.

37. Tarango-Hernández S, Alarcón-Rojo AD, Robles-Sánchez M, Guitérrez-Méndez N, Rodríguez-Figueroa JC. Short communication : Potential of Fresco-style cheese whey as a source of protein fractions with antioxidant and angiotensinI-converting enzyme inhibitory activities. J Dairy Sci 2015; 98(11): 7635-7639.

38. Peng $X$, Kong B, Yu H, Diao X. Protective effect of whey protein hydrolysates against oxidative stress in D-galactoseinduced ageing rats. Int Dairy J 2014; 34: 80-85.

39. Mann B, Kumari A, Kumar R, Sharma R, Prajapati K, Mahboob $S$, Athira $S$. Antioxidant activity of whey protein hydrolysates in milk beverage system. J Food Sci Technol 2014; 52(6): 3235-3241.

40. Peng X, Kong B, Xia X, Liu Q. Reducing and radical-scavenging activities of whey protein hydrolysates prepared with Alcalase. Int Dairy J 2010; 20(5): 360-365.

41. Rocha GF, Kise F, Rosso AM, Parisi MG. Potential antioxidant peptides produced from whey hydrolysis with an immobilized aspartic protease from Salpichroa origanifolia fruits. Food Chem 2017; 237: 350-355.

42. Abadía-García L, Castaño-Tostado E, Ozimek L, RomeroGómez S, Ozuna C, Amaya-Llano SL. Impact of ultrasound pretreatment on whey protein hydrolysis by vegetable proteases. Innov Food Sci Emerg Technol 2017; 37:84-90

43. Daliri EBM, Lee BH, Park BJ, Kim SH, Oh DH. Antihypertensive peptides from whey proteins fermented by lactic acid bacteria. Food Sci Biotechnol 2018, doi https://doi.org/10.1007/s10068018-0423-0.

44. Ashok NR, Aparna HS. Empirical and bioinformatic characterization of buffalo (Bubalus bubalis) colostrum whey peptides \& their angiotensin I- converting enzyme inhibition. Food Chem 2017; 228:582-594.

45. Hernández-Ledesma B, Dávalos A, Bartolomé B, Amigo L. Preparation of antioxidant enzymatic hydrolysates from alpha-lactalbumin and beta-lactoglobulin. Identification of active peptides by HPLC-MS/MS. I Agric Food Chem 2005; 53(3): 588-593.

46. Power O, Fernandez A, Norris R, Riera F, FitzGerald RJ. Selective enrichment of bioactive properties during ultrafiltration of a tryptic digest of $\beta$-lactoglobulin. J Funct Foods 2014; 9: 38-47.

47. Sah BNP, Vasiljevic T, McKechnie S, Donkor ON. Antioxidative and antibacterial peptides derived from bovine milk proteins. Crit Rev Food Sci Nutr 2016; 58(5): 726-740.

48. Smithers GW. Whey and whey proteins-from 'gutter-to-gold'. Int. Dairy J 2008; 18: 695-704.

49. Eigel WN, Butler JE, Ernstrom CA, Farrell HM, Harwalkar $V R$, Jenness R, McL Whitney R. Nomenclature of proteins of cow's milk: Fifth revision. J Dairy Sci. 1984; 67:1599-1631.

50. Brew K, Castellino FJ, Vanaman TC, Hill RL. The complete amino acid sequence of bovine $\alpha$-lactalbumin. J Biol Chem 1970; 10: 4570-4582.

51. Hernández-Ledesma B, Miguel M, Amigo L, Aleixandre MA, Recio I. Effect of simulated gastrointestinal digestion on the antihypertensive properties of synthetic beta-lactoglobulin peptide sequences. J Dairy Res 2007; 74(3): 336-339.

52. Sipola $M$, Finckenberg $P$, Vapaatalo $H$, Pihlanto-Leppälä $A$, Korhonen H, Korpela R, Nurminen ML. Alpha-lactorphin and beta-lactorphin improve arterial function in spontaneously hypertensive rats. Life Sci 2002; 71: 1245-1253.

53. Tsai JS, Chen TJ, Pan BS, Gong S Da, Chung MY. Antihypertensive effect of bioactive peptides produced by protease-facilitated lactic acid fermentation of milk. Food Chem 2008; 106: 552558.

54. Mullally MM, Meisel H, Fitzgerald RJ. Identification of a novel angiotensin-I-converting enzyme inhibitory peptides 
corresponding to a tryptic fragment of bovine $\beta$-lactoglobulin. FEBS Lett 1997; 402: 99-101.

55. Hernández-Ledesma B, Amigo L, Ramos M, Recio I. Release of angiotensin converting enzyme-inhibitory peptides by simulated gastrointestinal digestion of infant formulas. Int Dairy J 2004; 14(10): 889-898.

56. Pan D, Guo Y. Optimization of sour milk fermentation for the production of ACE-inhibitory peptides and purification of a novel peptide from whey protein hydrolysate. Int Dairy J 2010; 20(7): 472-479.

57. Lacroix IME, Meng G, Cheung IWY, Li-Chan ECY. Do whey protein-derived peptides have dual dipeptidyl-peptidase IV and angiotensin I-converting enzyme inhibitory activities? I Funct Foods 2016; 21: 87-96.

58. O'Keeffe MB, Conesa C, FitzGerald RJ. Identification of angiotensin converting enzyme inhibitory and antioxidant peptides in a whey protein concentrate hydrolysate produced at semi-pilot scale. Int J Food Sci Technol 2017; 52(8): 17511759.

59. Hernández-Ledesma B, Recio I, Ramos M, Amigo L. Preparation of ovine and caprine-lactoglobulin hydrolysates with ACEinhibitory activity. Identification of active peptides from caprine-lactoglobulin hydrolyzed with thermolysin. Int Dairy J 2002; 12(10): 805-812.

60. Korhonen H, Pihlanto A. Bioactive peptides: Production and functionality. Int Dairy I 2006; 16(9): 945-960.

61. Didelot S, Bordenave-Juchereau S, Rosenfeld E, Fruitier-Arnaudin I, Piot JM, Sannier F. Preparation of angiotensin-I-converting enzyme inhibitory hydrolysates from unsupplemented caprine whey fermentation by various cheese microflora. Int Dairy J 2006; 16: 976-983.

62. Fernández-Musoles R, Salom JB, Martínez-Maqueda D, López-Díez JI, Recio I, Manzanares P. Antihypertensive effects of lactoferrin hydrolyzates: Inhibition of angiotensin- and endothelin-converting enzymes. Food Chem 2013; 139(1-4): 994-1000.
63. Silveira ST, Martínez-Maqueda D, Recio I, Hernández-Ledesma B. Dipeptidyl peptidase-IV inhibitory peptides generated by tryptic hydrolysis of a whey protein concentrate rich in B-lactoglobulin. Food Chem 2013; 141(2): 1072-1077.

64. Song JJ, Wang Q, Du M, Ji XM, Mao XY. Identification of dipeptidyl peptidase-IV inhibitory peptides from mare whey protein hydrolysates. J. Dairy Sci 2017; 100: 1-10.

65. Pandey M, Kapila R, Kapilka S. Osteoanabolic activity of whey-derived anti-oxidative (MHIRL and YVEEL) and angiotensin-converting enzyme inhibitory (YLLF, ALPMHIR, IPA and WLAHK) bioactive peptides. Peptides 2018; 99:1-7.

66. Zhang $Q X, W u H$, Ling $Y F, L u R R$. Isolation and identification of antioxidant peptides derived from whey protein enzymatic hydrolysate by consecutive chromatography and Q-TOF MS. J Dairy Res 2013; 80(3): 367-373.

67. Corrêa APF, Daroit DJ, Fontoura R, Meira SMM, Segalin J, Brandelli A. Hydrolysates of sheep cheese whey as a source of bioactive peptides with antioxidant and angiotensin-converting enzyme inhibitory activities. Peptides 2014; 61: 48-55.

68. Pellegrini A, Dettling C, Thomas U, Hunziker P. Isolation and characterization of four bactericidal domains in the bovine $\beta$-lactoglobulin. Biochim Biophys Acta - Gen Subj 2001; 1526(2): 131-140.

69. Demers-Mathieu V, Gauthier SF, Britten M, Fliss I, Robitaille $G$, Jean J. Antibacterial activity of peptides extracted from tryptic hydrolyzate of whey protein by nanofiltration. Int Dairy J 2013; 28(2): 94-101.

70. Almaas H, Eriksen E, Sekse C, Comi I, Flengsrud R, Holm H, Jensen $E$, Jacobsen $M$, Langsurd T, Vegarud E. Antibacterial peptides derived from caprine whey proteins, by digestion with human gastrointestinal juice. Br J Nutr 2011; 106(6): 896-905.

71. Pellegrini A, Thomas U, Bramaz N, Hunziker $P$, Von Fellenberg $R$. Isolation and identification of three bactericidal domains in the bovine $\alpha$-lactalbumin molecule. Biochim Biophys Acta-Gen Subj 1999; 1426: 439-448. 